\title{
Children's Eating Attitudes Test (ChEAT): a validation study in Finnish children
}

\author{
Sohvi Lommi ${ }^{1} \cdot$ Heli T. Viljakainen ${ }^{1,2}\left(\mathbb{D} \cdot\right.$ Elisabete Weiderpass ${ }^{1,3,4,5,6}(\mathbb{D}) \cdot$ Rejane Augusta de Oliveira Figueiredo ${ }^{1,3}(\mathbb{C}$
}

Received: 14 February 2019 / Accepted: 9 May 2019 / Published online: 22 May 2019

(c) The Author(s) 2019

\begin{abstract}
Purpose To validate the Children's Eating Attitudes Test (ChEAT) in the Finnish population.

Materials and methods In total 339 children (age 10-15 years) from primary schools in Southern Finland were evaluated at two time points. They answered the ChEAT and SCOFF test questions, and had their weight, height and waist circumference measured. Retesting was performed 4-6 weeks later. Test-retest reliability was evaluated using intra-class correlation (ICC), and internal consistency was examined using Cronbach's alpha coefficient (C-alpha). ChEAT was cross-calibrated against SCOFF and background variables. Factor analysis was performed to examine the factor structure of ChEAT.

Results The 26-item ChEAT showed high internal consistency (C-alpha 0.79), however, a 24-item ChEAT showed even better internal consistency (C-alpha 0.84) and test-retest reliability (ICC 0.794). ChEAT scores demonstrated agreement with SCOFF scores $(p<0.01)$. The mean ChEAT score was higher in overweight children than normal weight $(p<0.001)$. Exploratory factor analysis yielded four factors (concerns about weight, limiting food intake, pressure to eat, and concerns about food), explaining $57.8 \%$ of the variance.

Conclusions ChEAT is a valid and reliable tool for measuring eating attitudes in Finnish children. The 24-item ChEAT showed higher reliability than the 26-item ChEAT.

Level of evidence Level 5, cross-sectional, descriptive study.
\end{abstract}

Keywords Adolescents · Children · Children's Eating Attitudes Test · ChEAT · Validation · Finland

\section{Introduction}

Elisabete Weiderpass and Rejane Augusta de Oliveira Figueiredo equal contribution.

Rejane Augusta de Oliveira Figueiredo

rejane.figueiredo@helsinki.fi

1 Folkhälsan Institute of Genetics, Folkhälsan Research Center, Helsinki, Finland

2 Department of Food and Environmental Sciences, University of Helsinki, Helsinki, Finland

3 Faculty of Medicine, University of Helsinki, Helsinki, Finland

4 Department of Research, Cancer Registry of Norway, Institute of Population-Based Cancer Research, Oslo, Norway

5 Department of Medical Epidemiology and Biostatistics, Karolinska Institutet, Stockholm, Sweden

6 Department of Community Medicine, Faculty of Health Sciences, University of Troms $\varnothing$, The Arctic University of Norway, Troms $\varnothing$, Norway
Increases in the prevalence of both obesity and disordered eating are a public health concern and might be associated [1-3]. Unhealthy eating attitudes and behaviors, such as dieting, vomiting and food avoidance, are considered disordered eating symptoms (DES) [4]. Eating disorder behaviors may eventually evolve into an eating disorder (ED) or a weight disorder (overweight and obesity), and therefore is of major public health relevance [5]. ED includes anorexia nervosa, bulimia nervosa, binge eating disorder, and other specified feeding and eating disorders [6].

Among 12- to 19-year-old adolescents, the prevalence of DES may range 9-17\% [7, 8], while among 12-20 year olds the prevalence of ED has been estimated around 3-4\% [9-11]. Although, in general, DES and ED are more common among females than males [10,12], the female-to-male ratio increases during puberty [13].

DES in childhood and adolescence is likely to continue into young adulthood $[12,14]$ and is associated with being 
overweight or obese, and having poor mental health and ED later in life [14-16]. Eating disturbance has been reported to start as early as the age of 9 years $[17,18]$. For early recognition of DES, a reliable scale to identify DES in children is needed.

There are several instruments that can be used to assess DES in children, such as the SCOFF [19], the Eating Disorder Examination Questionnaire (EDE-Q) [20], the Eating Disorder Examination Questionnaire adapted for children (ChEDE-Q8) [21], the Eating Disorder Inventory for children (EDI-C) [22], the Kids' Eating Disorders Survey (KEDS) [23], and the Children's Eating Attitudes Test (ChEAT) [24]. ChEAT has been previously utilized in large cohort studies [25, 26], and it has been validated in Spain [27, 28], Portugal [29], Belgium [30], Japan [31], and the USA [24, 32, 33]. ChEAT has also been successfully used in Sweden [34]; however, to our knowledge, it has not yet been validated in Finland or in any of the other Nordic countries.

The aim of the present study is to validate ChEAT in a community sample of 10- to 15-year-old Finnish school children. This study is a part of the Finnish Health in Teens (Fin-HIT) cohort study.

\section{Methods}

\section{Participants}

The present study, conducted by Folkhälsan Research Center in Helsinki, was initiated to validate ChEAT among Finnish children. ChEAT was used in the Fin-HIT cohort to evaluate disordered eating symptoms [35], and it was chosen as it had been successfully validated in several countries, as described above, and utilized in several previous studies (e.g., $[17,34,36])$. The Fin-HIT is a prospective cohort with approximately 11,000 9- to 14-year-old participants across Finland. The proposed validation sub-study consisted of 339 children at the same age as children in the Fin-HIT cohort at baseline. Figure 1 shows the participant selection flowchart. Participants were recruited from 12 primary schools in the Helsinki metropolitan area, and the data collection was conducted between October 2017 and March 2018. After receiving recruitment permission from municipal education administration and the principal of each school, fieldworkers introduced the study protocol and distributed invitations to children in suitable classes. To participate, children and one parent per each child provided a written informed consent. The Coordinating Ethics Committee of the Hospital District of Helsinki and Uusimaa has approved the study protocol.

\section{Data collection}

The data collection was conducted at two time points during normal school days: an initial visit and a retest visit 4-6 weeks later. Participants answered a questionnaire consisting of ChEAT, a question related to overeating symptoms (frequency of having eaten too much within a short time) [37], SCOFF and a short food frequency questionnaire. Instructions to fill in the questionnaire were explained simultaneously to all participants, and possible questions arising

Fig. 1 Flowchart of study

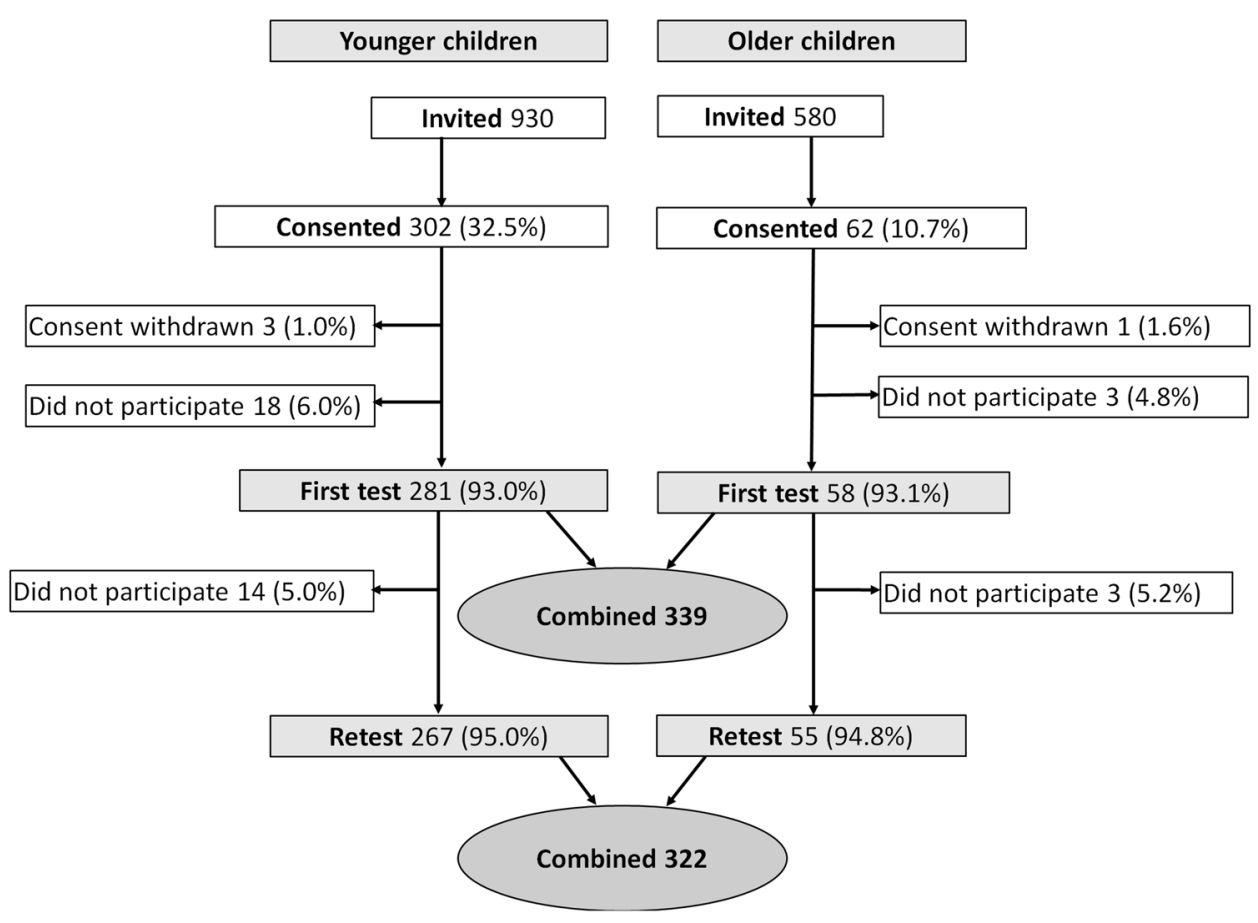


afterward were answered individually. After completing the questionnaire, at the first visit only, participants' weight, height and waist circumference were measured by trained fieldworkers. Due to absence from school, some participants filled in the questionnaire and took their measurements at home. We have previously shown the validity of home-based measures of weight, height, and waist circumference, and these were found to be reliable [38]. Of the 339 participants who attended the first data collection, 6 participated at home, and of the 322 retested participants, 16 participated at home.

\section{Study sample size}

Sample size calculations were based on ChEAT scores obtained from children in the Fin-HIT cohort (mean 6.1, standard deviation 4.7) [25]. Adopting a significance level of $5 \%$ and a power of $80 \%$, the minimum required sample size calculated was 214 children, allowing us to compare the results between the two time points (test and retest) and to test the internal consistency of the scale. We recruited children in 5th to 8th grades, but since the response rate was low among children in 7 th and 8 th grades (hereafter referred to as older children), we chose to carry out the study with children in 5th and 6th grades (hereafter referred to as younger children). The adequate sample size was met with younger children. The 58 older children were included as a complementary sample.

\section{Measures}

\section{ChEAT}

ChEAT is a self-administered questionnaire for assessing eating attitudes and behaviors in children, based on the Eating Attitudes Test (EAT-26) used in adults [39]. Since some wordings of EAT-26 items were deemed incomprehensible to children, a simplified version was developed and validated [24]. ChEAT consists of 26 items scored on a 6-point Likert scale with answer options 'never', 'rarely', 'sometimes', 'often', 'usually', and 'always'. To calculate the scale's scores, the categories 'never', 'rarely', and 'sometimes' were scored as zero, 'often' as one, 'usually' as two, and 'always' as three. Item 19 was reverse-scored, as suggested by Maloney [24]. The maximum score is 78 points. The higher the score, the higher the possibility for DES. The original ChEAT had three subscales: "Dieting", "Bulimia and Food Preoccupation" and "Oral Control", respectively, with 13, 6, and 7 items [39]. ChEAT was created and validated in English. The instrument used in Fin-HIT cohort and in the present study was evaluated by the research group and the final version was translated into Finnish by linguistic professionals. The scale adaptation for Finnish-speaking children was performed at the beginning of the Fin-HIT study.

\section{SCOFF}

The questionnaire also included SCOFF, a screening tool for detecting DES, consisting of five items that are dichotomously scored (yes $=1$, no $=0$ ). Two or more "yes" responses indicate DES [19]. The acronym SCOFF is composed of the following questions: (1) do you make yourself Sick because you feel uncomfortably full?; (2) do you worry you have lost Control over how much you eat?; (3) have you recently lost more than $6 \mathrm{~kg}$ (one stone) in a 3-month period?; (4) do you believe yourself to be Fat when others say you are too thin?; and (5) would you say that Food dominates your life? SCOFF was used to assess the concurrent validity since it was validated and used in several Finnish studies $[40,41]$.

\section{Anthropometric measurements}

Weight, height and waist circumference were measured by field workers in a standardized way. Weight was measured to the nearest $0.01 \mathrm{~kg}$ with a portable digital scale (CAS model PB), and height to the nearest $0.1 \mathrm{~cm}$ with a portable stadiometer (Seca model 217). Digital scale was calibrated daily before each series of measurements. Before measurements, the participants removed their shoes, heavy sweaters, and any objects from their pockets. Fieldworkers reported the clothing participants were wearing, and the weight of the clothes was subtracted from the measured weight in a standardized way. Waist circumference was measured midway between the hip bones and ribs to the nearest $0.1 \mathrm{~cm}$ with a measuring tape calibrated against a measure approximately once a week. Waist measurement was repeated twice, and the recorded waist circumference was calculated as their mean. In cases with more than $1 \mathrm{~cm}$ difference between the two measurements, a third measurement was performed and the mean was calculated based on all three measurements.

Body mass index (BMI) was calculated as weight $(\mathrm{kg}) /$ height $(\mathrm{m})^{2}$, and the children were classified as underweight, normal weight, overweight, or obese according to age- and sex-specific cut-offs suggested by the International Obesity Task Force (IOTF) [42]. Information on age and gender was obtained from the consent form and the questionnaire.

\section{Statistical analysis}

All associations between categorical variables were assessed using Chi-square tests. Comparison of quantitative variables with dichotomous variables was carried out using Student's $t$ test. ChEAT was evaluated for 300 children who answered all ChEAT items. Comparisons between ChEAT score and BMI categories were performed by generalized linear models using Poison distribution. The internal consistency of all scale items was assessed using Cronbach's alpha coefficient 
Table 1 Characteristics of all children and separated by age groups

\begin{tabular}{|c|c|c|c|c|c|c|c|}
\hline & \multirow{2}{*}{\multicolumn{2}{|c|}{ All children }} & \multicolumn{4}{|c|}{ Age group } & \multirow[t]{3}{*}{$p$ value } \\
\hline & & & \multicolumn{2}{|c|}{ Younger children } & \multicolumn{2}{|c|}{ Older children } & \\
\hline & $n$ & $\%$ & $n$ & $\%$ & $n$ & $\%$ & \\
\hline \multicolumn{8}{|l|}{ Gender } \\
\hline Girls & 185 & 54.6 & 155 & 55.2 & 30 & 51.7 & 0.632 \\
\hline Boys & 154 & 45.4 & 126 & 44.8 & 28 & 48.3 & \\
\hline \multicolumn{8}{|l|}{ BMI } \\
\hline Underweight & 41 & 12.1 & 36 & 12.8 & 5 & 8.6 & 0.664 \\
\hline Normal weight & 246 & 72.6 & 201 & 71.5 & 45 & 77.6 & \\
\hline Overweight & 49 & 14.5 & 41 & 14.6 & 8 & 13.8 & \\
\hline Obese & 3 & 0.9 & 3 & 1.1 & 0 & 0.0 & \\
\hline \multicolumn{8}{|l|}{ School size } \\
\hline$<300$ students & 91 & 26.8 & 91 & 32.4 & 0 & 0.0 & $<0.001$ \\
\hline$>300$ students & 248 & 73.2 & 190 & 67.6 & 58 & 100.0 & \\
\hline \multicolumn{8}{|l|}{ DES $(\mathrm{SCOFF} \geq 2)$} \\
\hline No DES & 284 & 89.3 & 232 & 88.2 & 52 & 94.5 & 0.167 \\
\hline \multirow[t]{2}{*}{ DES } & 34 & 10.7 & 31 & 1.8 & 3 & 5.5 & \\
\hline & Mean & SD & Mean & SD & Mean & SD & \\
\hline ChEAT score (26 items) & 2.55 & 4.22 & 2.66 & 4.44 & 2.05 & 2.84 & 0.319 \\
\hline Age (years) & 11.9 & 0.9 & 11.6 & 0.6 & 13.3 & 0.7 & $<0.001$ \\
\hline Waist circumference $(\mathrm{cm})$ & 65.4 & 7.4 & 64.6 & 7.2 & 69.3 & 7.1 & $<0.001$ \\
\hline Weight $(\mathrm{kg})$ & 44.6 & 10.3 & 42.8 & 9.1 & 53.0 & 11.6 & $<0.001$ \\
\hline
\end{tabular}

$B M I$ body mass index, $D E S$ disordered eating symptoms, $S D$ standard deviation

Table 2 Results of the test and retest analysis for all children and separated by age groups

\begin{tabular}{|c|c|c|c|c|c|c|c|}
\hline & \multicolumn{2}{|c|}{ ChEAT score (test) } & \multicolumn{2}{|c|}{$\begin{array}{l}\text { ChEAT score } \\
\text { (retest) }\end{array}$} & \multirow[t]{2}{*}{$\begin{array}{l}\text { Paired } t \text { test ( } p \\
\text { value) }\end{array}$} & \multirow[t]{2}{*}{$\begin{array}{l}\text { Pearson cor- } \\
\text { relation }\end{array}$} & \multirow[t]{2}{*}{ ICC } \\
\hline & Mean & SD & Mean & SD & & & \\
\hline \multicolumn{8}{|l|}{ 26-item ChEAT } \\
\hline All children & 2.55 & 4.22 & 2.40 & 3.91 & 0.331 & 0.771 & 0.769 \\
\hline Younger children & 2.66 & 4.44 & 2.45 & 4.10 & 0.266 & 0.780 & 0.779 \\
\hline Older children & 2.05 & 2.84 & 2.16 & 2.83 & 0.774 & 0.680 & 0.670 \\
\hline \multicolumn{8}{|l|}{ 24-item ChEAT } \\
\hline All children & 2.03 & 4.13 & 1.80 & 3.81 & 0.119 & 0.796 & 0.794 \\
\hline Younger children & 2.12 & 4.37 & 1.86 & 3.99 & 0.129 & 0.797 & 0.795 \\
\hline Older children & 1.57 & 2.73 & 1.53 & 2.83 & 0.717 & 0.784 & 0.784 \\
\hline
\end{tabular}

$I C C$ intra-class correlation, $S D$ standard deviation
(C-alpha), evaluating the correlation of each item with all the other items together.

To evaluate the factorial structure of all items and to identify different subscales in ChEAT, we used exploratory factor analysis. A model's goodness-of-fit was evaluated by the Kaiser-Meyer-Olkin (KMO) and Bartlett's sphericity tests, considering values over 0.70 and $p<0.05$, respectively, as acceptable [43]. Once the factors were identified, confirmatory factor analysis (CFA) was used to check the scale's factor structures. Estimations for CFAs were carried out using a robust unweighted least squares method. The goodnessof-fit of these two models was assessed using the following measures: Chi-square test, comparative fit index (CFI), nonnormed fit index (NNFI), root mean square error (RMSEA), standardized mean square residual (SRMR), goodness-of-fit index (GFI), and adjusted goodness-of-fit index (AGFI) [44].

Test-retest results were evaluated using paired $t$ tests to compare mean scores, Pearson correlation and intra-class correlation (ICC) to evaluate reliability and homogeneity of results between the two time points. 
Table 3 Comparison of ChEAT score by SCOFF score, binge eating symptom, gender, and body mass index (BMI) categories for all children and separated by age groups

\begin{tabular}{|c|c|c|c|c|c|c|c|c|c|c|c|c|}
\hline & \multicolumn{3}{|l|}{ All } & \multirow[t]{2}{*}{$p$ value } & \multicolumn{3}{|c|}{ Younger } & \multirow[t]{2}{*}{$p$ value } & \multicolumn{3}{|c|}{ Older } & \multirow[t]{2}{*}{$p$ value } \\
\hline & $n$ & Mean & SD & & $n$ & Mean & SD & & $n$ & Mean & SD & \\
\hline \multicolumn{13}{|l|}{ 26-item ChEAT } \\
\hline \multicolumn{13}{|l|}{ SCOFF } \\
\hline No DES & 246 & 1.85 & 2.58 & $<0.001$ & 198 & 1.87 & 2.58 & 0.010 & 48 & 1.79 & 2.58 & 0.005 \\
\hline DES & 31 & 6.94 & 9.29 & & 28 & 6.96 & 9.67 & & 3 & 6.67 & 5.51 & \\
\hline \multicolumn{13}{|c|}{ Frequency of having eaten too much in short time } \\
\hline Never & 212 & 1.94 & 2.94 & 0.013 & 174 & 1.90 & 2.93 & 0.009 & 38 & 2.13 & 3.00 & 0.769 \\
\hline Sometimes in a month & 79 & 3.68 & 5.89 & & 64 & 4.11 & 6.34 & & 15 & 1.87 & 2.80 & \\
\hline \multicolumn{13}{|l|}{ Gender } \\
\hline Girls & 163 & 2.88 & 5.04 & 0.061 & 134 & 3.06 & 5.39 & 0.051 & 29 & 2.07 & 2.83 & 0.971 \\
\hline Boys & 135 & 1.99 & 3.05 & & 110 & 1.98 & 3.07 & & 25 & 2.04 & 3.02 & \\
\hline \multicolumn{13}{|l|}{ BMI } \\
\hline Underweight & 36 & 2.00 & 2.06 & $<0.001^{\mathrm{a}}$ & 32 & 2.16 & 2.08 & $<0.001^{\mathrm{a}}$ & 4 & 0.75 & 1.50 & 0.150 \\
\hline Normal & 218 & 2.31 & 3.41 & & 176 & 2.36 & 3.56 & & 42 & 2.10 & 2.68 & \\
\hline Overweight/obese & 44 & 3.70 & 7.88 & & 36 & 3.97 & 8.49 & & 8 & 2.50 & 4.38 & \\
\hline \multicolumn{13}{|l|}{ 24-item ChEAT } \\
\hline \multicolumn{13}{|l|}{ SCOFF } \\
\hline No DES & 284 & 1.47 & 2.50 & 0.004 & 232 & 1.50 & 2.54 & 0.009 & 52 & 1.33 & 2.34 & 0.001 \\
\hline DES & 34 & 6.29 & 9.14 & & 31 & 6.26 & 9.48 & & 3 & 6.67 & 5.51 & \\
\hline \multicolumn{13}{|c|}{ Frequency of having eaten too much in short time } \\
\hline Never & 243 & 1.52 & 2.90 & 0.009 & 202 & 1.52 & 2.92 & 0.008 & 41 & 1.54 & 2.81 & 0.919 \\
\hline Sometimes in a month & 88 & 3.22 & 5.69 & & 72 & 3.57 & 6.12 & & 16 & 1.63 & 2.68 & \\
\hline \multicolumn{13}{|l|}{ Gender } \\
\hline Girls & 185 & 2.27 & 4.83 & 0.235 & 155 & 2.43 & 5.12 & 0.186 & 30 & 1.43 & 2.79 & 0.999 \\
\hline Boys & 154 & 1.73 & 3.10 & & 126 & 1.74 & 3.19 & & 28 & 1.71 & 2.71 & \\
\hline \multicolumn{13}{|l|}{ BMI } \\
\hline Underweight & 41 & 1.32 & 2.13 & $<0.001^{\mathrm{b}}$ & 36 & 1.50 & 2.21 & $<0.001^{\mathrm{a}}$ & 5 & 0.00 & 0.00 & 0.069 \\
\hline Normal & 246 & 1.80 & 3.22 & & 201 & 1.85 & 3.36 & & 45 & 1.58 & 2.48 & \\
\hline Overweight/obese $^{\mathrm{a}}$ & 52 & 3.67 & 7.52 & & 44 & 3.89 & 7.98 & & 8 & 2.50 & 4.38 & \\
\hline
\end{tabular}

$S D$ standard deviation, $D E S$ disordered eating symptoms, $B M I$ body mass index

${ }^{a}$ Multiple comparison between overweight and other groups $p<0.001$

${ }^{\mathrm{b}}$ Multiple comparison between all BMI categories $p<0.05$

We used the Lavaan package in R for CFA and SPSS statistical software (version 24.0) for all other statistical analyses. We adopted a 5\% statistical significance level for all tests.

\section{Results}

\section{Descriptive}

Of the 339 participants, $82.9 \%(n=281)$ were younger and $17.1 \%(n=58)$ older children. The overall mean age of participants was $11.9(\mathrm{SD} \pm 0.9)$ years: $11.6( \pm 0.6)$ years for younger and $13.3( \pm 0.7)$ years for older children. Overall, $54.6 \%(n=185)$ were girls and $45.4 \%(n=154)$ were boys.
Table 1 shows the main characteristics of all participants, and comparisons between younger and older children. Gender, BMI and presence of disordered eating did not differ between younger and older children.

\section{Internal consistency}

Cronbach's alpha coefficient (C-alpha) showed high internal consistency (C-alpha 0.79) for the 26-item ChEAT, however, the reverse-scored item 19 (I can show self-control around food) and the item 25 (I enjoy trying new rich foods) had a negative correlation with other items. A negative correlation indicates a reverse direction of these items related to the other items, suggesting that they should not be included in the final scale (called the 24-item ChEAT). 
After exclusion of the two items, the internal consistency increased (C-alpha 0.84). The internal consistency was also evaluated separately for younger and older children, and there was improvement in the $\mathrm{C}$-alpha after exclusion in both groups: increasing from 0.81 to 0.84 in younger children, and from 0.64 to 0.73 in older children.

\section{Test and retest}

Table 2 shows results for test and retest analysis. We found no statistical difference between test and retest in the mean total ChEAT scores, either with the 26-item ChEAT $(p=0.331)$ or the 24 -item ChEAT $(p=0.119)$. The results remained similar when stratified by age group. When evaluating the homogeneity between the two time points using ICC, the overall homogeneity was higher with the 24-item ChEAT (ICC 0.794) than with the 26-item ChEAT (ICC 0.769). Similar results were obtained when separated by age group (Table 2).

\section{Cross-calibrating ChEAT against SCOFF and other variables}

We compared the mean score of ChEAT with the mean score of SCOFF and with the presence of the overeating symptom (frequency of having eaten too much in a short time) using the $t$ test (Table 3). We found that the mean ChEAT score is higher in children with DES based on SCOFF than in children without DES $(p<0.01)$. Similar results were observed among the different age groups. Children with overeating at least once a month had higher ChEAT scores than children without overeating $(p=0.013)$. We obtained the same results among younger children $(p=0.009)$, but not with older children $(p=0.769)$.

Mean ChEAT scores were also compared between genders and BMI groups. The mean ChEAT score did not differ between genders $(p=0.061)$, but did differ between BMI categories $(p<0.001)$ : higher scores were related with higher BMI. Similar results were obtained when using the 24-item ChEAT score (Table 3).

\section{Exploratory and confirmatory factor analysis}

After excluding the two items from the scale, we performed a factor analysis to evaluate the factorial structure. Factor analysis identified four subscales (i.e., four factors; Table 4) with high adaptability to the original data $(\mathrm{KMO}=0.775$ and $p<0.001$ for Bartlett's sphericity test), and these explained $57.8 \%$ of the data variability.

We used CFA to verify the scale structure with three different approaches: (1) a model with the original structure; (2) a model with the original structure excluding
Table 4 Loads for new 24-item ChEAT factors after exploratory factor analysis

\begin{tabular}{lrrrr}
\hline & Factor 1 & Factor 2 & Factor 3 & Factor 4 \\
\hline Item 1 & 0.494 & 0.073 & 0.191 & 0.036 \\
Item 6 & 0.438 & -0.075 & 0.347 & 0.202 \\
Item 7 & 0.614 & 0.343 & 0.064 & 0.160 \\
Item 10 & 0.814 & -0.025 & 0.182 & -0.063 \\
Item 11 & 0.630 & 0.329 & 0.117 & -0.061 \\
Item 12 & 0.534 & 0.148 & 0.242 & 0.165 \\
Item 13 & 0.307 & -0.005 & 0.182 & 0.091 \\
Item 14 & 0.786 & -0.054 & -0.032 & -0.089 \\
Item 17 & 0.600 & 0.114 & -0.106 & 0.426 \\
Item 18 & 0.421 & 0.089 & 0.017 & 0.165 \\
Item 22 & 0.427 & -0.052 & -0.020 & 0.231 \\
Item 23 & 0.542 & 0.187 & -0.055 & 0.137 \\
Item 24 & 0.316 & 0.195 & -0.046 & 0.151 \\
Item 2 & 0.141 & 0.586 & 0.424 & 0.100 \\
Item 4 & 0.418 & 0.660 & -0.043 & 0.270 \\
Item 5 & 0.013 & 0.607 & 0.069 & -0.120 \\
Item 9 & 0.034 & 0.642 & -0.081 & 0.365 \\
Item 26 & 0.048 & 0.894 & 0.081 & -0.077 \\
Item 8 & 0.001 & 0.020 & 0.526 & -0.089 \\
Item 15 & 0.178 & 0.276 & 0.451 & -0.086 \\
Item 20 & 0.380 & 0.364 & 0.455 & 0.149 \\
Item 21 & -0.023 & -0.051 & 0.748 & 0.258 \\
Item 3 & 0.092 & 0.061 & 0.024 & 0.715 \\
Item 16 & 0.159 & 0.011 & 0.096 & 0.332 \\
\hline & & & &
\end{tabular}

items 19 and 25; and (3) a model with a new structure with four factors as suggested by the exploratory factor analysis (Table 5). In all children, model 1 showed the poorest goodness-of-fit compared with models 2 and 3 for all measures. Both model 2 and 3 showed high goodnessof-fit in all children, according to the following measures: CFI, NNFI, RMSEA, Chi-square, GFI and AGFI [44]. Similar results were obtained in the subgroup of younger children. The sample size was not large enough to evaluate models separately in the older children. After checking the goodness-of-fit of model 3, we evaluated the standard factor loads estimated by the CFA (Table 6), interpreted the results and named the four factors accordingly: subscale 1 as "Concerns about weight"; subscale 2 as "Limiting food intake"; subscale 3 as "Pressure to eat"; and subscale 4 as "Concerns about food". To cross-validate our results, we carried out the CFA with 11,407 children from Fin-HIT cohort, and found similar results: even though the results for the 26-item scale (model 1) were good, the results for the 24-item scale were even better (model 2 and 3) (Table 5). 
Table 5 Results of confirmatory factorial analysis for three different models evaluated in the study for all children and younger children

\begin{tabular}{|c|c|c|c|c|}
\hline & $\begin{array}{l}\text { Model } 1 \\
\text { (26 items-original) }\end{array}$ & $\begin{array}{l}\text { Model } 2 \\
\text { (24 items-original) }\end{array}$ & $\begin{array}{l}\text { Model } 3 \\
\text { (24 items-4 } \\
\text { new factors) }\end{array}$ & Criteria [44] \\
\hline \multicolumn{5}{|l|}{ All children } \\
\hline CFI & 0.872 & 0.959 & 0.955 & $\mathrm{CFI} \geq 0.90$ \\
\hline NNFI & 0.859 & 0.953 & 0.948 & $\mathrm{NNFI} \geq 0.90$ \\
\hline RMSEA & 0.028 & 0.016 & 0.017 & RMSEA $<0.08$ \\
\hline SRMR & 0.101 & 0.102 & 0.091 & $\mathrm{SRMR}<0.08$ \\
\hline Chi-square & 0.003 & 0.167 & 0.144 & $p$ value $>0.05$ \\
\hline GFI & 0.976 & 0.974 & 0.971 & $\mathrm{GFI} \geq 0.95$ \\
\hline AGFI & 0.970 & 0.966 & 0.963 & $\mathrm{AGFI} \geq 0.90$ \\
\hline \multicolumn{5}{|c|}{ Younger children } \\
\hline CFI & 0.842 & 0.941 & 0.959 & $\mathrm{CFI} \geq 0.90$ \\
\hline NNFI & 0.826 & 0.932 & 0.953 & $\mathrm{NNFI} \geq 0.90$ \\
\hline RMSEA & 0.032 & 0.021 & 0.017 & RMSEA $<0.08$ \\
\hline SRMR & 0.112 & 0.113 & 0.102 & $\mathrm{SRMR}<0.08$ \\
\hline Chi-square & 0.001 & 0.110 & 0.194 & $p$ value $>0.05$ \\
\hline GFI & 0.970 & 0.971 & 0.966 & $\mathrm{GFI} \geq 0.95$ \\
\hline AGFI & 0.962 & 0.960 & 0.957 & $\mathrm{AGFI} \geq 0.90$ \\
\hline \multicolumn{5}{|c|}{ Cross-validation analysis-using Fin-HIT data $(n=11,407)$} \\
\hline CFI & 0.950 & 0.969 & 0.991 & $\mathrm{CFI} \geq 0.90$ \\
\hline NNFI & 0.891 & 0.965 & 0.944 & $\mathrm{NNFI} \geq 0.90$ \\
\hline RMSEA & 0.041 & 0.043 & 0.038 & RMSEA $<0.08$ \\
\hline SRMR & 0.054 & 0.056 & 0.057 & SRMR $<0.08$ \\
\hline Chi-square & 0.098 & 0.076 & 0.072 & $p$ value $>0.05$ \\
\hline GFI & 0.990 & 0.980 & 0.986 & $\mathrm{GFI} \geq 0.95$ \\
\hline AGFI & 0.989 & 0.976 & 0.982 & $\mathrm{AGFI} \geq 0.90$ \\
\hline
\end{tabular}

CFI comparative fit index, NNFI non-normed fit index, RMSEA root mean square error, SRMR standardized mean square residual, GFI goodness-of-fit index, $A G F I$ adjusted goodness-of-fit index

\section{Discussion}

The present study validated the ChEAT scale in a population of Finnish children and proposed a new 24-item ChEAT. We identified new subscales to evaluate different aspects of DES in children. Validation was conducted with different approaches, all showing good consistency and reliability.

We evaluated the internal consistency of the original 26-item scale and observed two items (19 'I can show self-control around food' and 25 'I enjoy trying new rich foods') having an inverse correlation with all other items, indicating a semantic inversion of the statements, thus suggesting that these items were not clear for all children. The inverse correlation of the reverse-scored item 19 could be due to response bias, since the participants may have had a tendency to reply to this item in the same direction as to the other items. By excluding these two items, the reliability of the scale improved. The CFA reinforced these findings, since a better goodness-of-fit was observed with the 24-item scale. The exclusion of one or both of these items have been suggested by others too [24, 30, 31, 33], resulting in improved consistency.

We cross-calibrated ChEAT with other variables that have been associated with DES in previous studies. The SCOFF is a widely used, validated screening tool in clinical settings in Finland [41, 45, 46]. We observed that the mean ChEAT score was higher among those who scored higher in SCOFF. The ChEAT also discriminated between children with overeating and without overeating. Previous studies show that overweight children are more likely to have DES [47, 48], and our result of overweight children having higher ChEAT scores than normal weight children was in line with these. We also compared ChEAT score by gender but did not find any difference, which is consistent with results from some earlier studies [28, 49]. However, DES is shown to be more frequent in girls than boys in some studies [50,51], but the gender difference is proposed to emerge around the age of 13 [52-54].

The mean ChEAT scores in our sample were lower than observed in previous studies $[31,33,55]$. The majority of 
Table 6 Confirmatory factorial analysis results for 24-item ChEAT

\begin{tabular}{|c|c|}
\hline Item & $\begin{array}{l}\text { Standardized } \\
\text { estimation }\end{array}$ \\
\hline \multicolumn{2}{|l|}{ Subscale 1 "concerns about weight" } \\
\hline 1-I am scared about being overweight & 0.451 \\
\hline 6 - I am aware of the energy (calorie) content in foods that I eat & 0.538 \\
\hline 7-I try to stay away from foods such as breads, potatoes, and rice & 0.536 \\
\hline 10 - I feel very guilty after eating & 0.703 \\
\hline 11 -I think a lot about wanting to be thinner & 0.615 \\
\hline 12-I think about burning up energy (calories) when I exercise & 0.664 \\
\hline 13-Other people think I am too thin & 0.310 \\
\hline 14-I think a lot about having fat on my body & 0.624 \\
\hline 17-I eat diet foods & 0.558 \\
\hline 18 - I think that food controls my life & 0.398 \\
\hline 22-I feel uncomfortable after eating sweets & 0.435 \\
\hline 23-I have been dieting & 0.517 \\
\hline 24-I like my stomach to be empty & 0.348 \\
\hline \multicolumn{2}{|l|}{ Subscale 2 "limiting food intake" } \\
\hline 2-I stay away from eating when I am hungry & 0.800 \\
\hline 4-I have gone on eating binges where I feel that I might not be able to stop & 0.690 \\
\hline 5-I cut my food into small pieces & 0.389 \\
\hline 9-I vomit after I have eaten & 0.483 \\
\hline 26-I feel I have to vomit after a meal & 0.604 \\
\hline \multicolumn{2}{|l|}{ Subscale 3 "pressure to eat" } \\
\hline 8 - I feel that others would like me to eat more & 0.237 \\
\hline 15-I take longer than others to eat my meals & 0.508 \\
\hline 20 - I feel that others pressure me to eat & 0.824 \\
\hline $21-$ I give too much time and thought to food & 0.395 \\
\hline \multicolumn{2}{|l|}{ Subscale 4 "concerns about food" } \\
\hline 3 -I think about food a lot of the time & 0.428 \\
\hline 16-I stay away from foods with sugar in them & 0.503 \\
\hline
\end{tabular}

our participants lived in a small or medium-sized city or in the rural areas of a large city, which could partly explain our findings since mean ChEAT scores have been observed to be higher in large cities than in small and medium-sized cities, possibly due to susceptibility to more social pressure and to emphasized media influence in larger cities [31]. It has been suggested that socioeconomic status affects the prevalence of DES $[56,57]$, which might explain low mean scores in our study. However, information on parental SES was not available here.

Our exploratory factor analysis yielded four factors or subscales that we named "Concerns about weight", "Limiting food intake", "Pressure to eat", and "Concerns about food" that describe relevant attitudes and behaviors. The factor structure was confirmed in the CFA. In previous studies, the typical number of factors has been four or five, which is in line with our results $[27,31,55,58-60]$. In some previous studies [27, 31, 61], factor analysis revealed a factor representing behaviors or thoughts related to purging. In our analysis, purging ('I vomit after I have eaten' and 'I have the urge to vomit after a meal') did not stand out as an independent factor, but rather was associated with behaviors related to controlling the amount of food eaten.

Typically, validation studies are performed without proper sample size calculations [62], but this study was performed with an adequate sample size. We used several statistical approaches to validate ChEAT. Complementarily, we cross-calibrated ChEAT against several background variables that included SCOFF, overeating symptom, BMI, and gender. Furthermore, a cross-validation analysis in 11,407 Fin-HIT participants confirmed the results of the CFA. Still, this study had some limitations. The low participation rate may cause some bias. The participants are likely to be more health-oriented than the non-participants [63, 64], which could be the reason for low mean ChEAT scores in general. The low participation rate might also be due to a lack of a systematic reminder to parents to participate. Teachers were asked to send a reminder to parents through a messaging system, but it was not ensured whether they actually sent them. Since we did not have ED diagnoses available, we 
were not able to evaluate a ChEAT cut-off for identifying DES. The number of studies investigating a suitable cut-off for children is limited [27, 28, 31]. Cut-offs varying from 10 to 20 have been tested in age groups between 9 and 17 $[27,28,31]$, but there is yet no consensus on an optimal cutoff. The Fin-HIT cohort will include data on ED diagnoses from national healthcare registers, thus it will be possible to determine a suitable cut-off for children in the future. Moreover, the restricted range of the ChEAT scoring could be a possible limitation in our study. However, the restricted range reduces correlation coefficient values [65], which in this study is not a problem as we yielded good correlation coefficients even with the restricted range.

To conclude, we assessed the consistency and reliability of the ChEAT using an adequate sample size among Finnish children. ChEAT is a valid and reliable tool to measure eating attitudes and behaviors in Finnish children in 5th and 6th grades (10-13 years). We proposed a 24-item ChEAT to be used in future studies among Finnish children.

Acknowledgements Open access funding provided by University of Helsinki including Helsinki University Central Hospital. We thank the children and their families who participated in the study, the teachers and principals of the schools, and the fieldworkers. We thank Signe and Ane Gyllenberg Foundation and Samfundet Folkhälsan for supporting the study.

Funding This study was funded by Signe and Ane Gyllenberg Foundation (40-2847-42).

\section{Compliance with ethical standards}

Conflict of interest The authors declare that they have no conflict of interest.

Ethical approval All procedures performed in studies involving human participants were in accordance with the ethical standards of the institutional and/or national research committee and with the 1964 Helsinki declaration and its later amendments or comparable ethical standards. The Coordinating Ethics Committee of the Hospital District of Helsinki and Uusimaa has approved the study protocol (169/13/03/00/10).

Informed consent Informed consent was obtained from all individual participants included in the study.

Permission The ChEAT has been reproduced with permission from Maloney et al. (1988). Reliability Testing of a Children's Version of the Eating Attitudes Test. Journal of the American Academy of Child and Adolescent Psychiatry.

Data availability The datasets generated and/or analyzed during the current study are available from the corresponding author on reasonable request.

Open Access This article is distributed under the terms of the Creative Commons Attribution 4.0 International License (http://creativeco mmons.org/licenses/by/4.0/), which permits unrestricted use, distribution, and reproduction in any medium, provided you give appropriate credit to the original author(s) and the source, provide a link to the Creative Commons license, and indicate if changes were made.

\section{References}

1. Bray I, Slater A, Lewis-Smith H et al (2018) Promoting positive body image and tackling overweight/obesity in children and adolescents: a combined health psychology and public health approach. Prev Med (Baltim) 116:219-221. https://doi. org/10.1016/j.ypmed.2018.08.011

2. Battle EK, Brownell KD (1996) Confronting a rising tide of eating disorders and obesity: treatment vs. prevention and policy. Addict Behav 21:755-765. https://doi.org/10.1016/0306-4603(96)00034 $-2$

3. da Luz FQ, Sainsbury A, Mannan H et al (2017) Prevalence of obesity and comorbid eating disorder behaviors in South Australia from 1995 to 2015. Int J Obes 41:1148-1153. https://doi. org/10.1038/ijo.2017.79

4. Culbert KM, Racine SE, Klump KL (2015) Research review: what we have learned about the causes of eating disorders - a synthesis of sociocultural, psychological, and biological research. J Child Psychol Psychiatry 56:1141-1164. https://doi.org/10.1111/ jcpp. 12441

5. Stice E, Ng J, Shaw H (2010) Risk factors and prodromal eating pathology. J Child Psychol Psychiatry Allied Discip 51:518-525. https://doi.org/10.1111/j.1469-7610.2010.02212.x

6. American Psychiatric Association (2013) Diagnostic and statistical manual of mental disorders, fifth edition: DSM-5, 5th edn. Author, Washington, DC

7. Bilali A, Galanis P, Velonakis E, Katostaras T (2010) Factors associated with abnormal eating attitudes among greek adolescents. J Nutr Educ Behav 42:292-298. https://doi.org/10.1016/j. jneb.2009.06.005

8. Yirga B, Assefa Gelaw Y, Derso T, Wassie MM (2016) Disordered eating attitude and associated factors among high school adolescents aged 12-19 years in Addis Ababa, Ethiopia: a crosssectional study. BMC Res Notes 9:503. https://doi.org/10.1186/ s13104-016-2318-6

9. Álvarez-Malé ML, Castaño IB, Majem LS (2015) Prevalencia de los trastornos de la conducta alimentaria en adolescentes de Gran Canaria. [Prevalence of eating disorders in adolescents from Gran Canaria]. Nutr Hosp 31:2283-2288. https://doi.org/10.3305/ nh.2015.31.5.8583

10. Smink FRE, Van Hoeken D, Oldehinkel AJ, Hoek HW (2014) Prevalence and severity of DSM-5 eating disorders in a community cohort of adolescents. Int J Eat Disord 47:610-619. https:// doi.org/10.1002/eat.22316

11. Merikangas KR, He J, Burstein M et al (2010) Lifetime Prevalence of Mental Disorders in US Adolescents: results from the National Comorbidity Survey Replication-Adolescent Supplement (NCSA). J Am Acad Child Adolesc Psychiatry 49:980-989. https://doi. org/10.1016/j.jaac.2010.05.017

12. Neumark-Sztainer D, Wall M, Larson NI et al (2011) Dieting and disordered eating behaviors from adolescence to young adulthood: findings from a 10-year longitudinal study. J Am Diet Assoc 111:1004-1011. https://doi.org/10.1016/j.jada.2011.04.012

13. Peebles R, Wilson JL, Lock JD (2006) How do children with eating disorders differ from adolescents with eating disorders at initial evaluation? J Adolesc Heal 39:800-805. https://doi. org/10.1016/j.jadohealth.2006.05.013

14. Herpertz-Dahlmann B, Dempfle A, Konrad K et al (2015) Eating disorder symptoms do not just disappear: the implications of adolescent eating-disordered behaviour for body weight and mental health in young adulthood. Eur Child Adolesc Psychiatry 24:675-684. https://doi.org/10.1007/s00787-014-0610-3

15. Kotler LA, Cohen P, Davies M et al (2001) Longitudinal relationships between childhood, adolescent, and adult eating disorders. 
J Am Acad Child Adolesc Psychiatry 40:1434-1440. https://doi. org/10.1097/00004583-200112000-00014

16. Wade KH, Kramer MS, Oken E et al (2017) Prospective associations between problematic eating attitudes in midchildhood and the future onset of adolescent obesity and high blood pressure. Am J Clin Nutr 105:306-312. https://doi.org/10.3945/ajcn.116.14169 7

17. Deleel ML, Hughes TL, Miller JA et al (2009) Prevalence of eating disturbance and body image dissatisfaction in young girls: an examination of the variance across racial and socioeconomic groups. Psychol Sch 46:767-775. https://doi.org/10.1002/ pits. 20415

18. Maloney MJ, McGuire J, Daniels SR, Specker B (1989) Dieting behavior and eating attitudes in children. Pediatrics 84:482-489

19. Morgan JF, Reid F, Lacey JH (1999) The SCOFF questionnaire: assessment of a new screening tool for eating disorders. BMJ 319:1467-1468. https://doi.org/10.1136/bmj.319.7223.1467

20. Carter JC, Stewart DA, Fairburn CG (2001) Eating disorder examination questionnaire: norms for young adolescent girls. Behav Res Ther 39:625-632. https://doi.org/10.1016/S0005 -7967(00)00033-4

21. Kliem S, Schmidt R, Vogel M et al (2017) An 8-item short form of the Eating Disorder Examination-Questionnaire adapted for children (ChEDE-Q8). Int J Eat Disord 50:679-686. https://doi. org/10.1002/eat.22658

22. Eklund K, Paavonen EJ, Almqvist F (2005) Factor structure of the Eating Disorder Inventory-C. Int J Eat Disord 37:330-341. https://doi.org/10.1002/eat.20097

23. Childress AC, Brewerton TD, Hodges EL, Jarrell MP (1993) The Kids' Eating Disorders Survey (KEDS): a study of middle school students. J Am Acad Child Adolesc Psychiatry 32:843850. https://doi.org/10.1097/00004583-199307000-00021

24. Maloney MJ, McGuire JB, Daniels SR (1988) Reliability testing of a children's version of the Eating Attitude Test. J Am Acad Child Adolesc Psychiatry 27:541-543. https://doi. org/10.1097/00004583-198809000-00004

25. de Figueiredo RAO, Simola-Ström S, Isomaa R, Weiderpass E (2018) Body dissatisfaction and disordered eating symptoms in Finnish preadolescents. Eat Disord. https://doi. org/10.1080/10640266.2018.1499335

26. Wade KH, Skugarevsky O, Kramer MS et al (2014) Prospective associations of parental smoking, alcohol use, marital status, maternal satisfaction, and parental and childhood body mass index at 6.5 years with later problematic eating attitudes. Nutr Diabetes 4:e100. https://doi.org/10.1038/nutd.2013.40

27. Rojo-Moreno L, García-Miralles I, Plumed J et al (2011) Children's eating attitudes test: validation in a sample of Spanish schoolchildren. Int J Eat Disord 44:540-546. https://doi. org/10.1002/eat.20855

28. Sancho C, Asorey O, Arija V, Canals J (2005) Psychometric characteristics of the Children's Eating Attitudes Test in a Spanish sample. Eur Eat Disord Rev 13:338-343. https://doi. org/10.1002/erv.643

29. del Teixeira MCB, Pereira ATF, Saraiva JMT et al (2012) Validação portuguesa do teste de atitudes alimentares para crianças [Portuguese validation of the children's eating attitudes test]. Rev Psiquiatr Clin 39:189-193. https://doi.org/10.1590/S0101 $-60832012000600002$

30. Theuwis L, Moens E, Braet C (2010) Psychometric quality of the Dutch version of the Children's Eating Attitude Test in a community sample and a sample of overweight youngsters. Psychol Belg 49:311. https://doi.org/10.5334/pb-49-4-311

31. Chiba H, Nagamitsu S, Sakurai R et al (2016) Children's Eating Attitudes Test: reliability and validation in Japanese adolescents. Eat Behav 23:120-125. https://doi.org/10.1016/j.eatbe h.2016.09.001
32. Erickson SJ, Gerstle M (2007) Developmental considerations in measuring children's disordered eating attitudes and behaviors. Eat Behav 8:224-235. https://doi.org/10.1016/j.eatbe h.2006.06.003

33. Smolak L, Levine MP (1994) Psychometric properties of the Children's Eating Attitudes Test. Int J Eat Disord 16:275-282. https://doi.org/10.1002/1098-108X(199411)16:3\%3c275:AIDEAT2260160308\%3e3.0.CO;2-U

34. Halvarsson K, Lunner K, Westerberg J et al (2002) A longitudinal study of the development of dieting among 7-17-year-old Swedish girls. Int J Eat Disord 31:32-42. https://doi.org/10.1002/eat.10004

35. de Figueiredo RAO, Simola-Ström S, Rounge TB et al (2018) Cohort profile - the Finnish Health in Teens (Fin-HIT) Study: a population-based study. Int J Epidemiol. https://doi.org/10.1093/ ije/dyy 189

36. Arija V, Ferrer-Barcala M, Aranda N, Canals J (2010) BDNF Val66Met polymorphism, energy intake and BMI: a follow-up study in schoolchildren at risk of eating disorders. BMC Public Health 10:363. https://doi.org/10.1186/1471-2458-10-363

37. Field AE, Taylor CB, Celio A, Colditz GA (2004) Comparison of Self-report to interview assessment of bulimic behaviors among preadolescent and adolescent girls and boys. Int J Eat Disord 35:86-92. https://doi.org/10.1002/eat.10220

38. Sarkkola C, Rounge TB, Simola-Ström S et al (2016) Validity of home-measured height, weight and waist circumference among adolescents. Eur J Public Health 26:975-977. https://doi. org/10.1093/eurpub/ckw133

39. Garner DM, Olmsted MP, Bohr Y, Garfinkel PE (1982) The eating attitudes test: psychometric features and clinical correlates. Psychol Med 12:871-878. https://doi.org/10.1017/S003329170 0049163

40. Hautala L, Helenius H, Karukivi M et al (2011) The role of gender, affectivity and parenting in the course of disordered eating: a 4-year prospective case-control study among adolescents. Int J Nurs Stud 48:959-972. https://doi.org/10.1016/j.ijnur stu.2011.01.014

41. Lähteenmäki S, Aalto-setälä T, Suokas JT et al (2009) Validation of the Finnish version of the SCOFF questionnaire among young adults aged 20 to 35 years. BMC Psychiatry 9:1-8. https://doi. org/10.1186/1471-244X-9-5

42. Cole TJ, Lobstein T (2012) Extended international (IOTF) body mass index cut-offs for thinness, overweight and obesity. Pediatr Obes 7:284-294. https://doi.org/10.1111/j.2047-6310.2012.00064 .X

43. Hair JF, Black WC, Babin BJ, Anderson RE (2010) Multivariate data analysis, 7th edn. Prentice Hall, Upper Saddle River

44. Schumacher RE, Lomax RG (2010) A beginner's guide to structural equation modeling, 3rd edn. Routledge, New York

45. Eating disorders. Current Care Guidelines. Working group appointed by the Finnish Medical Society Duodecim, the Finnish Society for Child and Adolescent Psychiatry and the Finnish Psychiatric Association. Helsinki: The Finnish Medical Society Duodecim, 2014 (referred October 10, 2018). http://www.kaypa hoito.fi. Accessed 10 Oct 2018

46. Hautala L, Alin J, Liuksila P-R et al (2006) SCOFF-syömishäiriöseulan reliabiliteetti ja rakennevaliditeetti murrosikäisten koululaisten seulonnassa [in Finnish]. Duodecim 122:2137-2144

47. Colton PA, Olmsted MP, Rodin GM (2007) Eating disturbances in a school population of preteen girls: assessment and screening. Int J Eat Disord 40:435-440. https://doi.org/10.1002/eat.20386

48. Tanofsky-Kraff M, Wilfley DE, Morgan CM et al (2004) Eating-disordered behaviors, body fat, and psychopathology in overweight and normal-weight children. J Consult Clin Psychol 72:53-61. https://doi.org/10.1037/0022-006X.72.1.53

49. Gonçalves S, Silva M, Gomes AR, Machado P (2012) Disordered eating among preadolescent boys and girls: the relationship with 
child and maternal variables. Nutrients 4:273-285. https://doi. org/10.3390/nu4040273

50. Ferreiro F, Seoane G, Senra C (2011) A prospective study of risk factors for the development of depression and disordered eating in adolescents. J Clin Child Adolesc Psychol 40:500-505. https ://doi.org/10.1080/15374416.2011.563465

51. Hautala LA, Junnila J, Helenius H et al (2008) Towards understanding gender differences in disordered eating among adolescents. J Clin Nurs 17:1803-1813. https://doi.org/10.111 1/j.1365-2702.2007.02143.x

52. Ferreiro F, Seoane G, Senra C (2012) Gender-related risk and protective factors for depressive symptoms and disordered eating in adolescence: a 4-year longitudinal study. J Youth Adolesc 41:607-622. https://doi.org/10.1007/s10964-011-9718-7

53. Sasson A, Lewin C, Roth D (1995) Dieting behavior and eating attitudes in Israeli children. Int J Eat Disord 17:67-72. https://doi. org/10.1002/1098-108X(199501)17:1\%3C67:AID-EAT2260170 109\%3E3.0.CO;2-B

54. Holm-Denoma JM, Hankin BL, Young JF (2014) Developmental trends of eating disorder symptoms and comorbid internalizing symptoms in children and adolescents. Eat Behav 15:275-279. https://doi.org/10.1016/j.eatbeh.2014.03.015

55. Ambrosi-Randić N, Pokrajac-Bulian A (2005) Psychometric properties of the eating attitudes test and children's eating attitudes test in Croatia. Eat Weight Disord 10:e76-e82. https://doi. org/10.1007/BF03327495

56. Palma-Coca O, Hernández-Serrato MI, Villalobos-Hernández A et al (2011) Association of socioeconomic status, problem behaviors, and disordered eating in Mexican adolescents: results of the Mexican National Health and Nutrition Survey 2006. J Adolesc Health 49:400-406. https://doi.org/10.1016/j.jadohealth .2011.01.019

57. Kim Y, Austin SB, Subramanian SV et al (2018) Risk factors for disordered weight control behaviors among Korean adolescents: multilevel analysis of the Korea Youth Risk Behavior Survey. Int J Eat Disord 51:124-138. https://doi.org/10.1002/eat.22820

58. Kelly C, Ricciardelli LA, Clarke JD (1999) Problem eating attitudes and behaviors in young children. Int J Eat Disord
25:281-286. https://doi.org/10.1002/(SICI)1098-108X(19990 4) $25: 3 \% 3 \mathrm{C} 281:$ AID-EAT5\%3E3.0.CO;2-T

59. Senra C, Seoane G, Vilas V, Sánchez-Cao E (2006) Comparison of 10- to 12-year-old boys and girls using a Spanish version of the children's eating attitudes test. Pers Individ Dif 42:947-957. https ://doi.org/10.1016/j.paid.2006.09.005

60. Ranzenhofer LM, Tanofsky-Kraff M, Menzie CM et al (2008) Structure analysis of the Children's Eating Attitudes Test in overweight and at-risk for overweight children and adolescents. Eat Behav 9:218-227. https://doi.org/10.1016/j.eatbeh.2007.09.004

61. Anton SD, Han H, Newton RL et al (2006) Reformulation of the Children's Eating Attitudes Test (ChEAT): factor structure and scoring method in a non-clinical population. Eat Weight Disord 11:201-210. https://doi.org/10.1007/BF03327572

62. Anthoine E, Moret L, Regnault A et al (2014) Sample size used to validate a scale: a review of publications on newly-developed patient reported outcomes measures. Health Qual Life Outcomes 12:176. https://doi.org/10.1186/s12955-014-0176-2

63. Bender AM, Jørgensen T, Pisinger C (2015) Is self-selection the main driver of positive interpretations of general health checks? The Inter99 randomized trial. Prev Med (Baltim) 81:42-48. https ://doi.org/10.1016/j.ypmed.2015.07.004

64. Cheung KL, Ten Klooster PM, Smit C et al (2017) The impact of non-response bias due to sampling in public health studies: a comparison of voluntary versus mandatory recruitment in a Dutch national survey on adolescent health. BMC Public Health 17:276. https://doi.org/10.1186/s12889-017-4189-8

65. Bland JM, Altman DG (2011) Correlation in restricted ranges of data. BMJ 342:d556. https://doi.org/10.1136/bmj.d556

Publisher's Note Springer Nature remains neutral with regard to jurisdictional claims in published maps and institutional affiliations. 